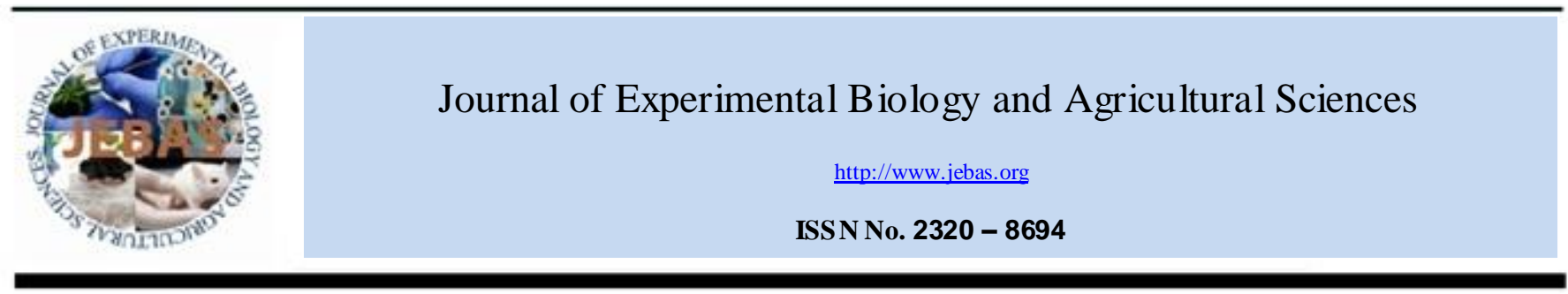

\title{
IMPACT OF BOTANICAL EXTRACTS ON HISTOPATHOLOGY OF SILKWORM (Bombyx mori L.)
}

\section{Mude Jagadish Naik* and Angothu Samba Naik}

Department of Zoology, Acharya Nagarjun a University, Guntur, AndhraPradesh-522510. India.

Received - March 19, 2015; Revision - April 18, 2015; Accepted - May 11, 2015

Available Online - June 19, 2015

DOI: http://dx.doi.org/10.18006/2015.3(3).281.287

\begin{abstract}
KEYWORDS
Mealy Bug

Plant Extracts

Fat body

Silk gland

CSR2

Bivoltine Hybrid

ABSTRAC T

Present study was conducted to find out the effect of various botanical extract on the tissue, cellular an d sub cellular level and histopathology of silkworm, findings of the present study gives useful data concerning the changes in the insect. Three plants extract viz Azadirachta indica, Ocimum sanctum and Parthenium hysterophorus were used as experimental while untreated leaves consider as control. These botanicals were sprayed on the tukra (Pink mealy bug) infected mulberry leaves and feed to silkworm (CSR2 bivoltine hybrid). Findings of the study suggested no change in the fat body of the silkworm feed on the botanical sprayed leaves and it was with normal vacuolization cytoplasm of cells. While hypertrophied nucleus fat body and voculated cytoplasm was reported in the silkworm fed on the tukra infected chawki leaves. The outer layers of the nucleolus were reported somewhat hypertrophied and cytoplasm was reported vacuolate with mild degeneration of cell in silkworm fed on the tukra infected leaves. Silk worm fed leaves revealed almost similar changes to that of normal and there was no change in botanical sprayed fed larvae. The impact in tissue of the silkworm when fed with normal and crude botanical extracts against mealy bugs shows normalcy, but in the tukra infected mulberry leaves fed by silk worms the tissues shows slight degenerative with nutritional impact upon them.
\end{abstract}

* Corresponding author
E-mail: jagadish100naik@ gmail.com (Mude Jagadish Naik)

Peer review under responsibility of Journal of Experimental Biology and Agricultural Sciences.

Production and Hosting by Horizon Publisher (www.my-

vision.webs.com/horizon.html).

All rights reserved.
All the article published by Journal of Experimental Biology and Agricultural Sciences is licensed under a Creative Commons Attribution-NonCommercial 4.0 International License Based on a work at www.jebas.org.

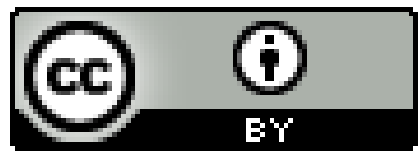




\section{Introduction}

Sustainability sericulture depends upon successful realization of mulberry plantation and rearing of cocoon crop. Various factors like plant diseases and pest affect the mulberry plantation; among these pests are the most dangerous one. Large numbers of chemical pesticides are available for the ruled out these harmful pests. But spray of these toxic chemicals directly or indirectly influence the rearing of silk worm and cocoon productivity.

Therefore, routine application of insecticides and pesticides protect the plants from the pests with the short period and however application of toxic chemical prolonged residual effects in mulberry gardens is restricted because of high sensitivity of silkworms (Dandin et al., 2003; Samuthiravelu et al.,2003; Sakthivel et al., 2010;Sambanaik \& jaga dishnaik,2012).

Some of sucking pests of mulberry viz. pink mealy bug, thrips, spiraling whitefly, etc. have been developed resistance against the available pesticides and because more dangers for mulberry. Furthermore these chemical pesticides also caused destruction of natural enemies of these pests. So, due to the development of resistance and destruction of natural enemy of mulberry pest, there is a need to develop an ecofriendly IPM approach against these well known mulberry pests. In this context, an effort has been made to investigate the efficacy of some promising botanicals against the major sucking pests of mulberry in the tropical zone of south India in the mulberry ecosystem.

Mealy bug Maconellicoccus hirstus (Family-Pseudococcidae) presence has been reported in and around Anantapur \& Krishna districts of Andhra Pradesh \& some places of Tamil Nadu and also reported in outer parts of India, Banglade sh and Indonesia. India and In donesian species of the mealy bug have been identified as Maconellicoccus hirstus (green). The tukra infected mulberry leaves with minute mealy bugs in mulberry garden shows symptoms with curling of apical leaves which the beetles feeds on plant sap and decreases the leaf protein and moisture status during summer seasons(Kumar et al.,1997).

Use of botanical extracts for controlling pests and nematodes is becoming appealing because of the growing problem of environmental pollution arising from the use of persistent pesticides (Shivakumar, 1995). There has been de-registration of some hazardous pests and nematicides with increasing pressure on farmers to use non-chemical pest control methods that do not pollute the environment. This emphasis the need for new methods of control such as the use of locally available traditional medicinal plants that are having volatile compounds of various locally available plant extracts in controlling pests has to be study and identify the use of local plant materials for the control of pests.

\section{Materials and Methods}

\subsection{Silkworm Rearing}

For the study, the popular south Indian cross breeds (CB) silk worm CSR2 of Bivoltine breed were use d as test materials. The disease free laying (DFLS) of this cross breed CSR2 (Bivoltine hybrid) were maintained under field conditions and brought to the laboratory.

\subsection{Mulberry Plantation}

Mulberry crop was maintained by following standard agronomic practices. Treatments were imposed on $15^{\text {th }}$ day of pruning in each plot, five plants were randomly selected and the population of pink mealy bug was counted. In each plant population was counted on three leaves (top, middle and bottom). The total number leaves per plant were also counted and the population was expressed as number per leaf. Observations were made just before spraying (pre-treatment count), 3, 5 and 7 days after spraying. The following plant extracts with naturally existing insecticidal properties were chosen for spray of mealybug infection in mulberry plants.

\subsection{Preparation of aqueous plant extract}

Plants having insecticidal properties like Azadirachata indica, Ocimum sanctum and Parthenium hysterophorus were taken from the department of Botany, University College of sciences, Acharya Nagarjuna University, Guntur, Andhra Pradesh. The leaves of plants were collected, washed thoroughly with distilled water the fresh leaves were homogenate with the help of mechanical device. Further 200 gm of crude selected plants were subjected to extraction through soxhlet apparatus with $500 \mathrm{ml}$ methanol solvent for $24 \mathrm{hrs}$. After $24 \mathrm{hrs}$ given extract was filtered and filtrate was evaporated completely. Evaporated extract material was dissolved in distilled water and diluted to $2.5 \%$ concentration and used for spray at the identified plot with earlier infection of mealy bug in mulberry plants. Botanical extracts sprayed to tukra leaves of various concentrations were fed to third instar larvae with four feeding per day. The feeding was maintained up to the earlier end of cocoon stage of the silkworm.

2.4 Microscopic examination used in Silkworm fed with botanical-Sprayed Mulberry leaves

An microscopic examination were carried out to find the effect of feeding healthy and botanical sprayed leaves on rearing silkworm hybrid (CSR2). Leaves were collected from the experimental plots $0,2,5,7,10,15$ and 20 days after spray and were fed to second instar larvae. From 3 to 6 days of silkworm tissues were taken for the present study. Morphological changes in silkworm exposed to different percentages of tukra infected and healthy mulberry leaves fed to silkworm and were analyzed and changes in tissue were photographed to observe the external symptoms and the histological sections of fat 
bodies and silk gland were taken. The fat bodies and silkgland of fifth instar of day 6 were isolated from normal and experimental batch. They were fixed in Bouin's fluid $(75 \mathrm{ml}$ saturated aqueous picric acid, $25 \mathrm{ml} 40 \%$ formaldehyde and $5 \mathrm{ml}$ glacial acetic acid) for 24 hours. The sections were stained with Harris hemotoxylin (Harris, 1900) and counter stained with eosin, dissolved in $95 \%$ alcohol. After dehydration and cleaning, the sections were mounted in Canada balsam. Photomicrographs of the sections preparation were taken using Olympus (PM - 6 model) photomicrography equipment.

\section{Results}

Microscopic examination was identified in tissues of silk worm fed with botanicals sprayed batch and there was no changes observed in fat body with normal vacuolization in cytoplasm of cells (Plate I-C, D). In the silkworm fat body, fed with tukra infected chawki leaves, the nucleus of fat body cells were shown larger i.e. hypertrophied that in the normal cells. Vacuoles appeared in the cytoplasm were somewhat less and the membranous sheath surrounding the fat cells were slightly destructed (Plate I-A, B). In silkworms fed with normal and botanical sprayed mulberry not showing any significant damage in the inner and middle layers (Plate II-C) and normal lacy of epidermal layer and vacuolization in the cells of outer layer was observed (Plate II-D). In the tukra infected leaves fed to silkworms the nuclei of the outer layer of the silkgland were slight by somewhat hyper trophied, vacuolization appeared in the cytoplasm with mild degree of degeneration of cells (Plate II-A) silkworm fed leaves revealed almost similar changes to that of normal and there were no change in botanical sprayed fed larvae but the epithelial layer is larger and completely pealed out and became thin at 6th day when fed with tukra infected leaves (Plate II-B).

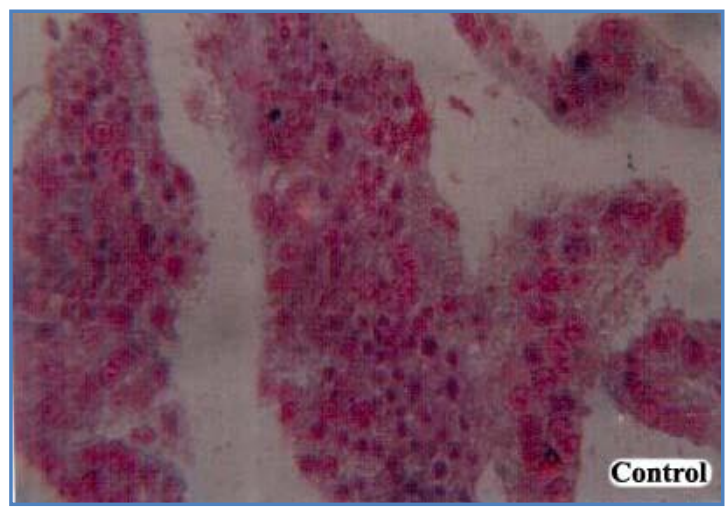

PLATE I Fat body - Transverse section of fat body of fifth instar at 5th day of CSR2 hybrid silk worm, Bombyx mori fed with nomal mulberry leaves $H \& E$, (100X\&400X).
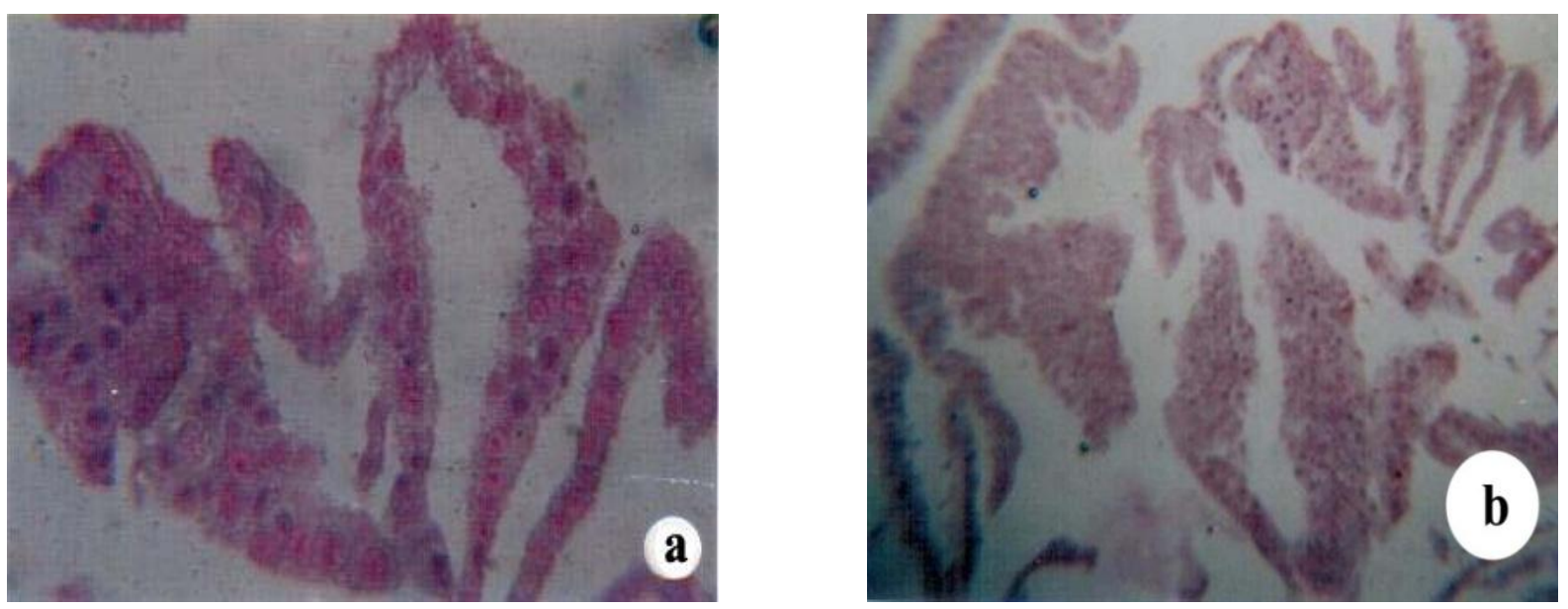

PLATE I Fat body a \& bTransverse section of fat body of fifth instar at 3 and 5 th day of CSR2 hybrid Silk worm, Bombyx mori fed with tukra mulberry leaves $H \& E$, (100X\&400X). 

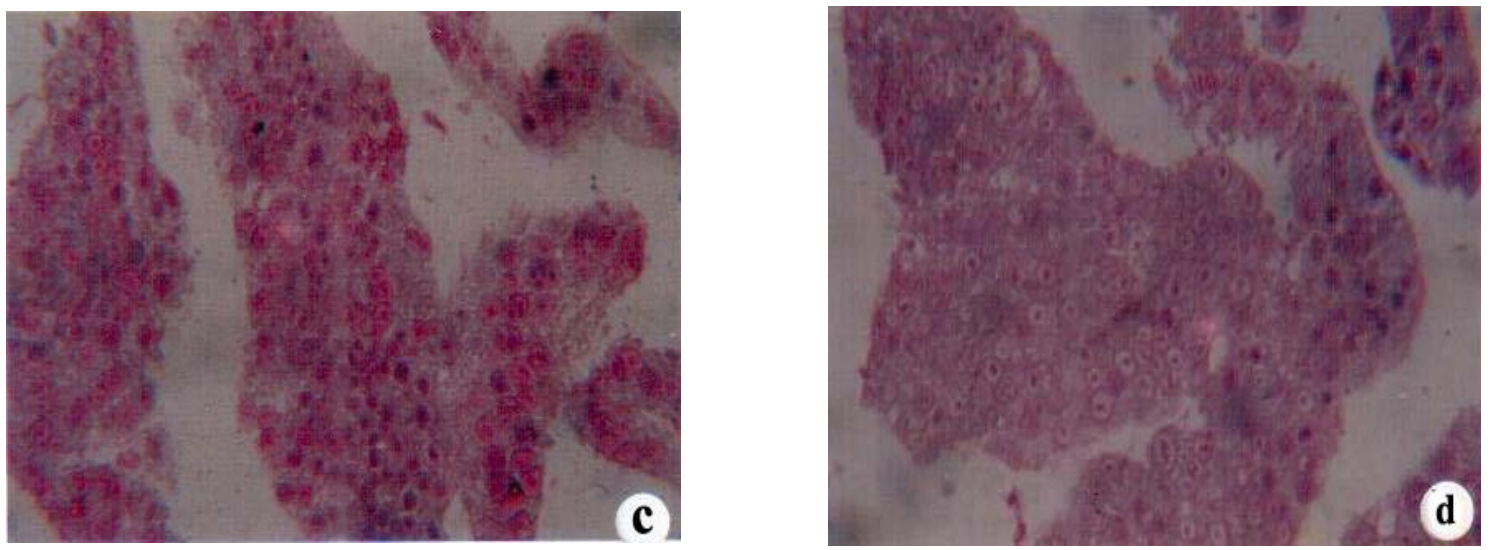

PLATE I Fat body c \& d Transverse section of fat body of fifth instar at 3 and 5 th day of CSR2 hybrid Silk worm, Bombyxmori fed with botanical extract sprayed mulberry leaves $H \& E,(100 X \& 400 X)$.

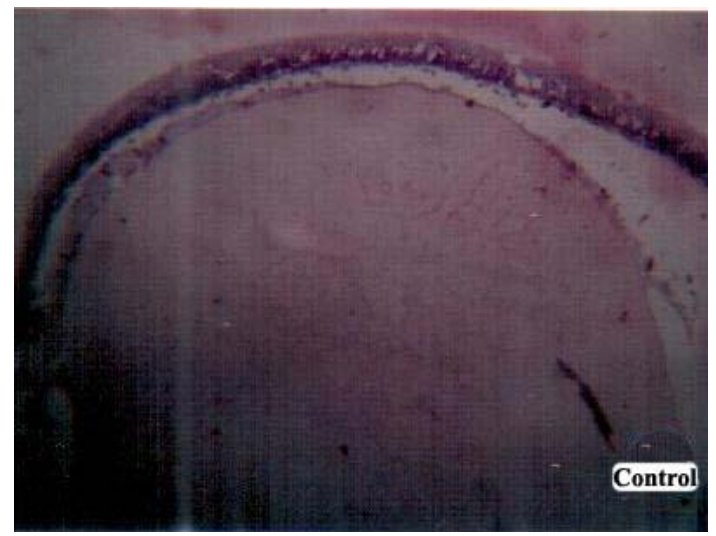

PLATE II Silk gland -Transverse section of silk gland of fifth instar at 5 th day of CSR2 hybrid Silk worm, Bombyxmori fed with nomal mulberry leaves $H \& E$, (100X\&400X).
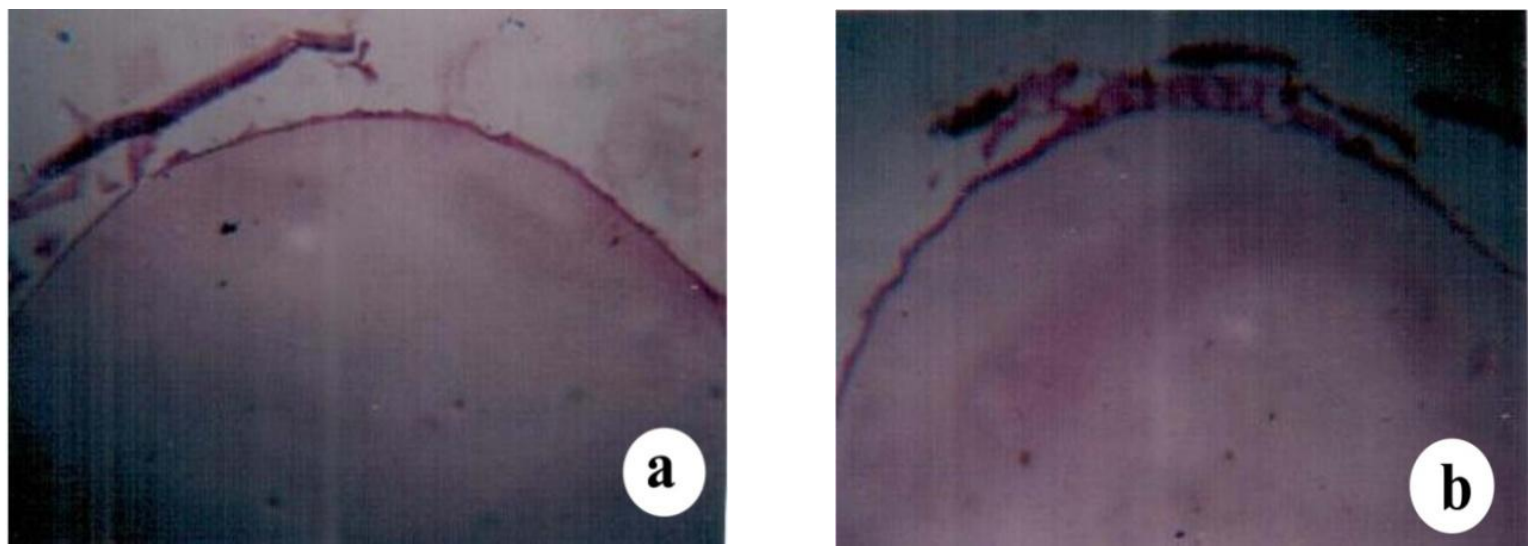

PLATE II Silk gland a \& b-Transverse section of silk gland of fifth instar at 3 and 5 th day ofCSR2 hybrid Silk worm, Bombyxmori fed with tukra mulberry leaves $H \& E,(100 X \& 400 X)$. 

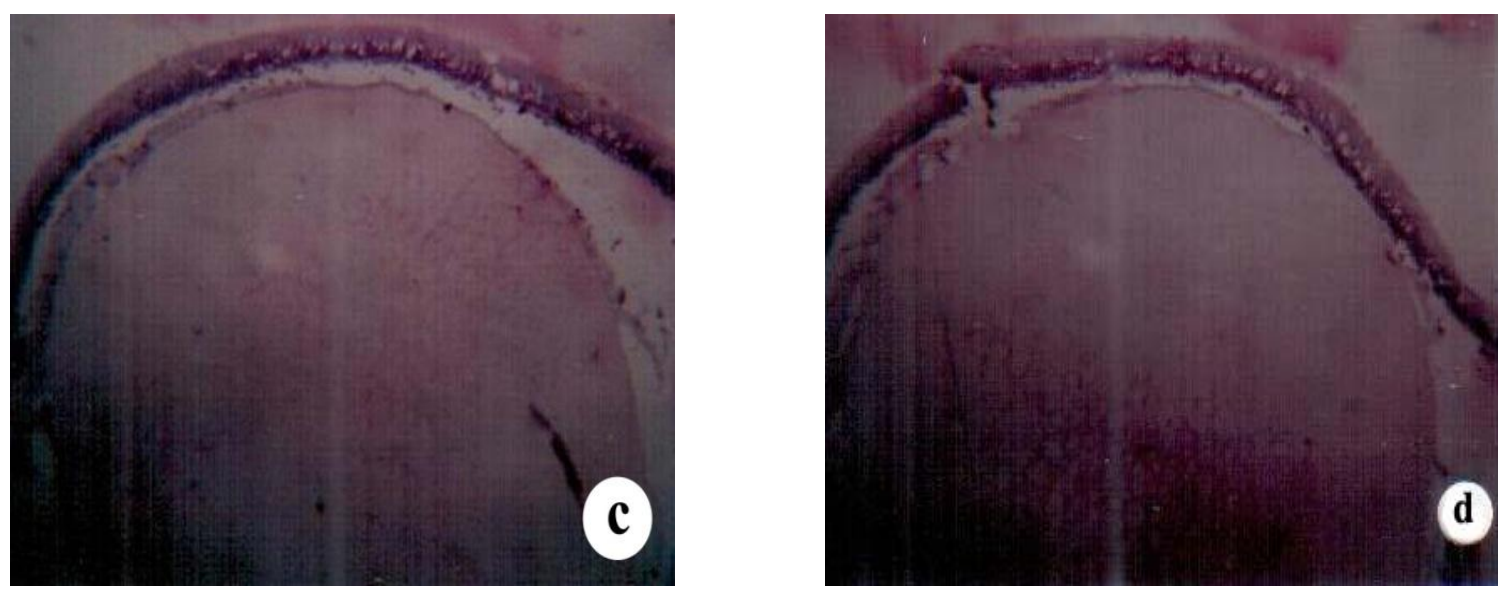

PLATE: II Silk gland c \& d- Transverse section of silk gland of fifth instar at 3 and 5 th day of CSR2 hybrid Silk worm, Bombyxmori fed with botanical extracts sprayed mulberry leaves $H \& E(100 X \& 400 X)$

\section{Discussions}

The silkworm, being a phytophagous insect feeds exclusively on mulberry leaf during its larval stages which account for nearly half of its total life span.The food that is consumed during larval stages utilized for growth as well as accumulation of energy reserves to fuel its metabolisms during non-feeding periods like larval moulting, spinning, pupal and adult stages of silkworm. The mealy bug, Maconcllicoccus hirsutus green has been considered the casual agent of tukra the exact nature of the development of tukra is not so far explained. Tukra was earlier believed to be a viral transmitted disease through the mealy bugs (Babu et al., 1994). The mealy bugs infected mulberry leaves when fed to silkworm the metabolites of phenylalamine ammonia lyses, showed marked increased in infected leaves when compared with healthy leaves fed to larvae (Muralikumaran \& Bhaskhran 1992; Ramarethinam \& San geetha, 2002; Mukhopadhyay , 2006; Babu et al., 2009; Sathyaseelan \& Bhaskaran, 2010).

The accurate diagnoses of silkworm based on the external symptoms are not specific and it requires microscopic examination of haemolymph and other tissues of the silkworms when it effects with malnutrition. Histological responses of silkworm at different level of feeding of tukra infected show variations in various physiological and biochemical activities. From the present study it is clear that malnutrition and water deficient leaf shows significant histological changes in different tissues of the hybrid silk worm CSR2. Ho wever, most of these changes occurred in fat body and some symptoms in the silk gland when fed with tukra normal and botanical extracts administrated on mulberry leaves (or) pest stress to silk worm when insect feeds.

On exposure of the hybrid silkworms at different levels with tukra disease d chawki leaves were showing a significant effect on the structure of the midgut wall at $3 \mathrm{rd}$ and 6th day while feeding of silk worm with botanicals did not show any variation and tissues they did not exhibit much variation because of these symptoms the food conversion efficiency has not decreased in the silkworm. Shiva Kumar (1995) reported a significant increase in the food conversion and body weight of the silkworm when feeding with normal mulberry or tukra leaves. The quality of proteins, carbohydrates available in mulberry leaves as determined by its composition of amino acids (Ito \& Arai, 1965) is of critical importance for growth and development of tissues in an insect (Vaandrager et al., 1989).

Fat body is the principal tissue for intermediary metabolism in insects. It is responsible for the considerable metabolic activity and is the main source for the haemolymph proteins, lipids and carbohydrates; those serve as precursors for various metabolic activities in other tissues. Silkworm fed with normal and sprayed mulberry leaves was not showing any change in the fat body and normal vacuolization appeared in cytoplasm of cells. The magnitude of these changes however, is more at day 5 th in tukra infected leaves when fed by silkworm. Valantina San gamithirai et al. (2014) had reported changes in fat bodies and silkgland of silk worm when fed it with V1 mulberry leaves treated with nano particles and supplements enhances the feed. Furthermore, Tadasumori et al. (1990) carried out microscopic study of biochemical and physiological function of the fat body in silkworm (B. mori) and reported that fat body of both fed with normal mulberry leaves and starved larva that the lipodial bodies decreased in number and become less electron dense in the fat body cell of starved larva. In the silkworm nucleus of fat body cells have been shown larger vacuoles in the cytoplasm were somewhat less and the membranous sheath surrounding the fat cells were slightly destructed when fed with tukra infected chawki leaves. Vail et al. (1973) observed that mealy bugs infestation in mulberry is more at tukra infected leaves with lack of biochemical components when fed on mulberry, insect cells is characterized by hypertrophy of the 
cell nucleus, cell enlargement and tissue dryness occurs. Umesh Kumar et al. (1990) reported that the damage of fat body cells shows the decrease of biochemical constituents of total lipids when fed with tukra and healthy mulberry leaves varied from one variety to another.

The silk gland which is second largest organ in the body occupies most of the ventro-lateral side of the body. When silk worm fed on the botanicals sprayed leaves, no damage was reported in the cells as compared to normal silkworm and there was no difference in the epidermal layer of this sign is due to acceleration of metabolic activity. The inner fibers in and sericin layers however are not infected which indicates that these layers could with stand without infestation of mealy bugs on mulberry at the time of feed to silkworms. The tukra diseased leaves when fed with silkworms the damage was restricted only to the outer layer and no marked differences are observed in inner layers depending upon the nutrition and impact of sprayed mulberry upon pests with mulberry feed or nutritionally normal as good healthy leaves taken by silkworm. Zhou et al.,1995; Centhilnayaki et al., 2004 \& Prabu (2011) reported that $\mathrm{V} 1$ treated with silver nano particles and various supplements fed to silkworm is having superior enhance to synthesize the secretary materials by silk gland.The mucus like substance is supposed to be released from the gland into the circulating blood from the $3 / 5$ of the Fifth instar larva. Sriharan et al. (1979) showed that at the time of de-saping mealy bug penetrate their stylet in the tender parts of the plant and the toxic saliva causes imbalance in the cell metabolism by silk worm.

Kumar \& Chakraborthy (1999) reported that feeding of silk worm with tukra infected leaves causes significant change in the integument, silk gland, haemolymph tissues of the silk worms. Singh et al., (2002) showed that utilization of tukra diseased mulberry leaves for silkworm rearing without affecting the quantitative characters has been discussed.

\section{Conclusion}

In the present investigation the impact of the crude extract on the silkworms tissues was tested and found that when silk worms fed with normal and crude botanical extracts against mealy bugs shows normalcy, but in the tukra infected mulberry leaves fed by silkworms the tissues shows slight degenerative with nutritional impact upon them.

\section{Conflict of Interest}

I am grateful to department of sericulture for providing the mulberry garden and valuable literature. I particularly would like to thank UGC-major research project (UGC-MRP) NEWDELHI for financial support.

\section{References}

Babu KR, Ramakrishna S, Reddy YHK, Lakshmi G, Naidu NV, Basha SS, Bhaskar M (2009) Metabolic alterations and molecular mechanism in silkworm larvae during viral infection: A review. African Journal of Biotechnology 8:899907. DOI: $10.5897 /$ AJB2009.000-9149.

Babu RS, Dorcus D, Vivekanandan M (1994) Possible Control of Tukra Disease in Mulberry Using Aqueo us Plant Extracts of Natural Pesticide Origin. The Journal of Sericultural Science of Japan 63: 175-182.

Chenthilnayaki N, Selvisabhanayakan G, Mathivanan V (2004) Development of issue on mulberry cultivation in relation to silk on mulberry cultivation in relation to silk production. Indian Journal of Environment and Ecoplanning 8:111-117.

Dandin S, Jayantjayaswal B, Giridhar K (2003) Hand book of Sericulture technologies, Central silk board, Bangalore, India Pp.53-56.

Harris HF (1900) Rapid conversion of haematoxylin into haematin in staining reactions. Journal of Applied Microscopy and Laboratory Methods 3: 777-782.

Ito T, Arai N (1965) Nutrition of silkworm Bombyx mori L. amino acid requirements and nutritive effects of various proteins. Bulletin of Sericultural Experiment Station 19:345373.

Kumar MVS, Chakraborthy N (1999) New record of native predator, Nephus sp. on Maconellicoccus hirsutus (Green). Journal of Advance Zoology 20: 56-58.

Kumar V, Tewari SK, Datta RK (1997) Dermal pores and wax secretion in mealybug Maconellicoccus hirsutus (Homiptera, Pseudococcidae) A pest of mulberry. Italian Journal of Zoology $64 \quad$ : 307- 311. Doi: http://dx.doi.org/10.1080/11250009709356218.

Mukhopadhyay SK (2006) Technologies for management of mulberry pests. In proccedings of Work shop on appropriate technology for Mulberry Sericulture,17th -18th January 2006 at Central Seri cultural Research and Training Institute, Berhampore, India Pp. 136-39.

Muralikumaran NV, Bhaskhran M (1992) Incidence of severity of Mealy bugs associated with mulberry leaf curl (tukra) in tamilnadu proceedings of National seminar on Sericulture, CSRTI Mysore, India. pp. 49-53.

Prabu PG, Sabhanayakam S, Mathivanan V, Balasundaram D (2011) Studies on the Gro wth Rate of Silk worm Bombyx mori (L.) (Lepidoptera: Bombycidae) Fed with Control and Silver Nanoparticles (AgNps) Treated MR2 Mulberry Leaves. International Journal of Industrial Entomology 22:39-44.

Ramarethinam S, Sangeetha N (2002) Defense related enzymes and metabolites in mulberry leaves in response to coinjestation by pink mealy bug and yellow mite. Journal of Pestology 26: 11-18. 
Sakthivel N, Balakrishna R, Ravikumar J, Samuthiravelu P, Isaiarasu L, Qadri SMH (2010) Efficacy of botanicals against jassid Empoasca flavescens F. (Homoptera: Cicadellidae) on mulberry and their biosafety to natural enemies. Journal of Biopesticides 5:246-249.

Sambanaik G, Jagadishnaik M (2012) Effect of Botanical Extracts against the tukra (Maconellicoccus hirsutus) Infested mulberry on Trehalose and Phosphorylase activity in Silkworm, Bombyx Mori L. IOSR Journal of Agriculture and veterinary Science 1: 50-53.

Samuthiravelu P, Suresh A, Jayaraj S (2003) Effect of botanical and biological control tactics against mulberry tukra mealy bug, Maconellicoccus hirsutus. Abstract of National Seminar on disease and pest management in Sericulture, conducted by Department of Sericulture, Chintamani College, Karnataka on 12-13September (2003) Pp.19-23.

Sathyaseelan V, Bhaskhran V (2010) Efficacy of Some Native botanical extracts on the repellency property against the pink mealy bug, Maconellicoccus Hirsutus (Green) In Mulberry Crop. Recent Research in Science and Technology 2:35-38

Shiva Kumar C (1995) Physiological and biochemical studies on nutrition in silkworm, Bombyx mori (L.) Ph.D. thesis, department of sericulture, submitted to Bangalore University, Bangalore, India.

Singh R, Raghavendra Rao D, Kariappa BK, Jaiswal KP (2002) Effect of feeding tukra infested mulberry leaves on the quantitative characters of mulberry silk worm, Bombyx mori $\mathrm{L}$. Bulletin Indian Academic Seric ulture 6: 91-95.

Sriharan TP, Sampson MV, Krishnas wami S (1979) Studies on the tukra disease (Maconellicoccus hirsuts) of mulberry silk worm. Indian Journal of Sericulture 18: 78-80.
Tadasumori J, Hiromu A, Masatoshi Kobayashi N (1990) Ultra structural changes of the fat body in the silkworm during post-embryonic development.Tokyo metropolitan Horticultural High School, Setagaya-Ku, Tokyo.Book of Sericultural Experimental Station Pp.23-29.

Umeshkumar NN, Shree MP, Muthegowdaboraiah G (1990) Changes in protein, carbohydrates in silkworm tissues when fed by tukra. Indian Journal of Sericulture 29: 93-100.

Vaan drager SH, Haller TB, Van Marre wijk WJA, Beenakkers AMT (1989) Fractionation and kinetic properties of trehalase from flight muscles and haemolymph of the locust, Locusta migratoria. Insect Biochemistry 19: 89-94. doi:10.1016/0020-1790(89)90013-9.

Vail PV, Jay DL, Hink WF (1973) Replication and infectivity of the nuclear polyhedrosis virus of the alfalfa looper, Autographa californica, produced in cells grown in vitro. Journal of Invertebrate Pathology 22: 231-237. doi:10.1016/0022-2011(73)90139-0.

Valantina Sangamithirai A, Selvi sabhanayakam, Susithra N, Ganeshprabhu N, Mathivanan S, Hemalatha S, Elanchezian C (2014) Studies on histological changes in fatbody and silk gland of silkworm, Bombyx mori (lepidoptera:bombycidae) fed with V1, mulberry leaves and nanoparticles treated leaves. International Journal of modern research and Reviews 2: $20-25$.

Zhou CH, Iwashita Y, Fukami M, Kawasaki H, Kanke E (1995) Histopathological observation on the larval midgut cells of the silkworm, Bombyx mori, poisoned by NaF. Journal of Sericulture Science, Japan 64: 344-351. 